\title{
Modeling of decay heat removal from CONSTOR RBMK-1500 casks during long-term storage of spent nuclear fuel
}

\author{
R. Poškas ${ }^{1,2}$, V. Šimonis ${ }^{1}$, H. Jouhara ${ }^{3}$ and P. Poškas ${ }^{1}$ \\ ${ }^{1}$ Lithuanian Energy Institute, Nuclear Engineering Laboratory, 3 Breslaujos, Kaunas LT44403, Lithuania.
}

${ }^{2}$ Kaunas University of Technology, Faculty of Mechanical Engineering and Design, Department of Thermal and Nuclear Energy, Studentu 56, Kaunas LT-51424, Lithuania.

${ }^{3}$ Brunel University London, Institute of Energy Futures, College of Engineering, Design and Physical Sciences, UB8 3PH Uxbridge, United Kingdom.

${ }^{*}$ Corresponding author: E-mail address: Robertas.Poskas@lei.lt , Tel.: +370 37401893. Full postal address: Lithuanian Energy Institute, Breslaujos str. 3, LT-44403 Kaunas, Lithuania

\begin{abstract}
Management of spent nuclear fuel is a very important part in the whole cycle of nuclear energy generation. Ignalina nuclear power plant operated two RBMK-1500 reactors that are now being decommissioned. After careful consideration "dry" storage technology in casks was selected for the interim storage of spent nuclear fuel (SNF) for up to 50 years. SNF after pre-storage time in water pools for not less than 5 years is loaded into cast-iron or metal-concrete casks. In this paper decay heat removal was modeled from specific GNB (Gesellschaft für Nuklear Behälter GmbH) metalconcrete (CONSTOR RBMK-1500) casks for the long-term storage period up to 300 years. The ALGOR code was used for the numerical modeling of the distribution of the heat fluxes and temperatures in a loaded cask placed in an open type storage facility in both summer and winter taking into account local environmental conditions. A local sensitivity analysis of the impact of fuel parameter uncertainties is also performed.
\end{abstract}

Keywords: RBMK-1500 spent nuclear fuel, metal-concrete CONSTOR cask, long-term storage, thermal analysis, local sensitivity analysis.

\section{Introduction}

Growing energy consumptions led to the soaring level of greenhouse gas generation. EU legislation requires that the generation of the greenhouse gas and waste is being curbed. So renewable and sustainable energy [1, $2,3]$ including nuclear energy are the sources that can solve these problems. When developing the nuclear energy it is very important the proper management of the spent nuclear fuel and radioactive waste.

Two water-cooled graphite-moderated channel-type power reactors RBMK-1500 were operated at the Ignalina Nuclear Power Plant (Ignalina NPP) in Lithuania from 1983 and 1987. Both reactors were shut down before the end of 2009 (at different times). "Dry" storage technology was selected for the interim storage of spent nuclear fuel (SNF). The SNF is loaded in cast-iron or metal-concrete casks and will be stored for approximately 50 years or maybe even longer.

At first, GNB (Gesellschaft für Nuklear Behälter GmbH, Germany) cast-iron CASTOR RBMK-1500 type casks were used (hereafter described in the paper as CASTOR casks). These casks are placed in open type storage. Later, less expensive metal-concrete CONSTOR RBMK-1500 type casks were selected (hereafter described in the paper as CONSTOR casks). The closed type storage facility that will store GNS (Gesellschaft für Nuklear-Service GmbH) design CONSTOR RBMK-1500/M2 type casks with much higher capacity compared to the containers currently in use has been in operation since 2017. The safety of the SNF storage depends on safe thermal conditions, radiation safety, and nuclear safety. Requirements for fuel bundles, casks and a storage facility will be met only if there is a full understanding of the processes taking place in casks and of the interaction between the casks and the environment.

Thermally, the maximum allowable temperatures of the cask's external surface and of fuel rod cladding are the key parameters that determine if the SNF storage and the cask handling are being performed safely. There are also limitations on the temperatures of construction materials for the casks. It has been established that $300^{\circ} \mathrm{C}$ [4] to $350^{\circ} \mathrm{C}$ [5] temperatures are the limiting temperatures for RBMK SNF cladding for long-term storage in an inert nitrogen or helium environment (i.e. for normal conditions). 
Three factors determine the thermal regime of a cask: the decay heat release from the SNF, cask design and its storage conditions. Nuclear fuel used at the Ignalina NPP was enriched to 2-2.8\% with and without an erbium absorber; $2 \%$ enriched fuel has been loaded in CASTOR and CONSTOR casks. A detailed analysis of radiological characteristics and the generation of decay heat for the RBMK-1500 fuel is presented in study [6]. It was demonstrated that during the first five to seven years when the fuel is usually stored in water pools the decay heat release generation is decreasing significantly. Later on there is a rather slow decrease in decay heat generation.

There are two types of the commercial storage casks: ventilated concrete casks and non-ventilated steel (or cast iron) casks for PWR and BWR SNF storage. In most cases thermal analysis of spent fuel storage casks have been performed for the interim storage period (about 50 years). It is possible to indicate few recent publications presenting thermal analysis of full scale ventilated concrete casks.

J. C. Lee et al. performed 3D thermal analysis of the ventilated SNF dry storage cask using Fluent code under normal and off-normal conditions [7]. Modeling was performed in two stages. In the first stage model consist of the cask body and storage canister with the known heat flux from the SNF. In the second stage the canister with fuel assemblies and fuel baskets is modelled using the modelled canister wall temperature from the first stage modelling. The porous models (for thermal conductivity and flow resistance) of the fuel assembly has been used to simplify calculations.

J. C. Lee et al. performed experimental investigations and 3D modelling [8] using Fluent code. Effective thermal conductivities for fuel assembly and a composite basket were developed to simplify 3D modelling. A porous media model was used to model flow field in the assemblies. It was indicated that maximum temperature (about $300{ }^{\circ} \mathrm{C}$ ) is at upper part of the central assembly.

Y. S. Tseng et al. [9] also modelled full-size vertical ventilated concrete storage cask. A homogeneous solid thermal model was used for a fuel assembly with effective thermal conductivity calculated in advance. Natural convection of helium was neglected in the canister. It is demonstrated that maximum temperature is located in the middle of the central assembly and in the accident it is $333{ }^{\circ} \mathrm{C}$.

J. Li and Y. Y. Liu [10] performed 3D thermal modelling of ventilated vertical storage cask for PWR SNF. The effects of the basket material (stainless steel or aluminium alloy), gas used in the canister (helium or nitrogen) and gas pressure in the canister (from 1 to $6 \mathrm{~atm}$ ) on the fuel assembly maximum cladding temperature and the canister surface temperatures have been analyzed. Modelling was performed using Ansys Fluent code. Effective thermal conductivity approach for a fuel assembly, which was modelled as solid block, was applied. Thermal radiation between surfaces in the cask was modelled using surface to surface (S2S) model. Natural convection in the canister and in the cask ventilation gap was analyzed.

There is a number of publications on the thermal analysis of the ventilated vertical concrete storage casks for WWER-1000 SNF [11, 12, 13]. In the modelling multistage approach is used. At first stage the basket with SNF assemblies is considered as a solid body with effective thermal properties and the thermal conditions of the whole storage cask are defined. Defined heat transfer coefficients on basket surface are used as boundary conditions at the second stage. At the second stage only basket is modelled and fuel assemblies are assumed as solid bodies with effective thermal properties. Thermal conditions on their surfaces are defined. As the third stage east SNF assembly is modelled and temperature fields of each fuel element are defined. The modelling results demonstrated that the assembly that is placed in the centre of the basket has the maximum temperature.

There is interest again to the thermal analysis of non-ventilated metal casks mainly because the experimental tests data becomes available. S. H. Yoo et al. [14], R. A. Brewster et al. [15] performed detailed modelling using Fluent code down to the fuel rods to compare within the effective thermal conductivity and porous media approximation for fuel assemblies but for a small scale models.

In a study [16], using the ALGOR (USA) numerical modeling code, thermal results were obtained for CASTOR and CONSTOR non-ventilated casks for an interim storage of RBMK-1500 SNF for period of 50 years. Thermal regimes for CASTOR and CONSTOR casks at different storage conditions were provided. The modeling included a single cask and a cask in a storage facility (influenced by the adjacent casks) just loaded with SNF (stored for 5 years in water pools) or being in storage for 50 years for winter or summer conditions, with or without an assessment of solar insolation.

R. Poškas et al. [17] analyzed the long-term extended storage of SNF (up to 300 years) in the cast iron non-ventilated CASTOR casks at the Ignalina NPP from a thermal point of view. A cask was modeled 
assuming it is at an open type storage facility in summer and winter conditions. The combined analysis also included the results [16] for interim storage up to 50 years. The analyses showed that the fuel load temperature decreases most significantly during the first 50 years of interim storage.

This paper presents the modeling results of decay heat removal from metal-concrete CONSTOR nonventilated casks during long-term storage (up to 300 years) that are used only for RBMK-1500 SNF at the Ignalina NPP. Modeling is performed for casks in an open type storage facility for summer and winter conditions. Modeling results provide inside into the temperature variation during long-term storage period and allows for estimation of its impact to the possible mechanical stresses and corrosion processes in such casks.

\section{Methodology}

The body of a CONSTOR cask (Figure 1(a)) contains 2 low-alloy steel cylinders of different inner (1a) and outer $(1 b)$ dimensions. The annular space is filled with heavy concrete $1 c$. The heavy concrete is also poured into the space between panels $1 d$ and $1 e$ at the bottom of the cask. A massive metal ring $1 f$ is welded at the top of cask steel cylinders. The cask lid 3 and two guard plates $4 a$ and $4 b$ are fastened and fixed to the ring.

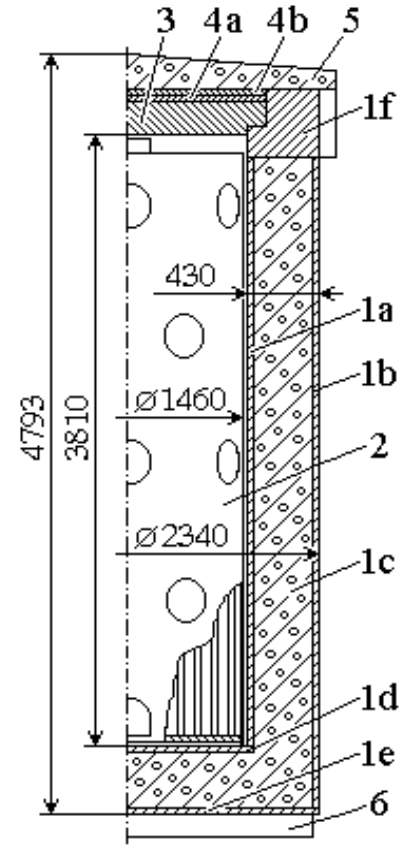

(a)

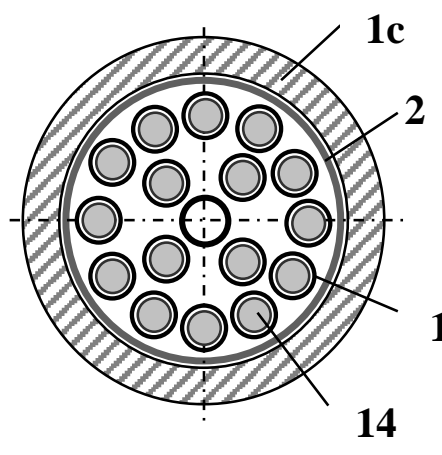

13

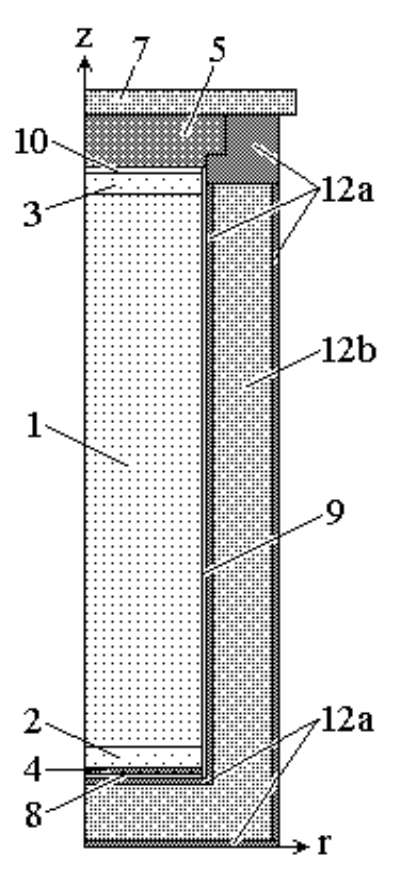

(b)

Fig. 1. Schematic view of the cask (a) and of the computer model (b). (a): 1a, 1b,1d, 1e, $1 f$ - metal parts of the cask's body, $1 c$ - heavy concrete filler, 2 - basket, 3 - lid, $4 a$, $4 b$ - guard plates, 5 - reinforced concrete cover, 6 - damper, 13 - tube of the basket, 14 - fuel rod bundle, 102 pcs.; (b): 1 - fuel load active part, 2, 3 fuel load lower and upper parts, 4 - basket bottom, 5 - lid, 7 - reinforced concrete cover, 8-10 - horizontal lower, vertical and horizontal upper helium gaps, $12 a$ - metal parts of the body, $12 b$ - heavy concrete.

The cask described is a storage vessel for a stainless steel basket 2 where the SNF bundles are placed. The basket contains 51 assemblies cut in halves (102 fuel rod bundles). Once the basket is within the cask, the cask lid and the guard plates are tightly closed. When the water is pumped out, the cask dries out and helium is pumped in. Then the cask is put onto a concrete base at the open storage facility and a reinforced concrete cover 5 is used as additional cover. A shock-absorbing damper 6 is fastened to the bottom of the cask to prevent possible shocks during its transfer to the storage site. A loaded concrete cask weights approx. 88 tonnes.

For thermal analysis, the ALGOR code was used. It is a general-purpose code which can be used for two- and three-dimensional modeling using the finite element method. ALGOR code is widely used for modeling of mechanical stress and structural integrity of the equipment $[18,19]$ and thermal processes $[20$, 21]. The cask in this paper was modeled as two-dimensional in cylindrical r-z coordinates assuming steady 
state conditions (Figure 1(b)). Modeling is performed based on effective thermal conductivities and thermal conductivities. So, in such case ALGOR code is rather effective tool.

The elements of the cask are meshed separately. The grid of the computer model was created following ALGOR code recommendations for the effective conductivity or conductivity cases. To demonstrate the grid independence the modelling was performed also using 1.5 times finer grid. In such case the maximum rod cladding temperature decreased by $1.5 \%$ but cask body outer surface temperature increased by $0.5 \%$. This demonstrates that selected grid is reasonable and gives conservative value for rod cladding temperature.

The modeling took into consideration the following processes and parameters: the decay heat of the fuel, heat conduction (or effective conductivity) coefficients of all materials of the cask (which depend on the temperature), ambient temperature, the influence of adjacent casks in the storage facility, the heat transfer coefficient by natural convection from the cask's outer surface, the emissivity for external radiation from the cask surfaces and the heat fluxes from solar insolation.

A cask just loaded with 102 SNF rod bundles that had been stored in water pools for 5 years emits approximately $6.1 \mathrm{~kW}$ of decay heat. In order to evaluate the axial decay heat variation (the maximum deviation is $17 \%$ ), the decay heat for homogeneous fuel loading was enlarged by $17 \%$, and assumed to be $Q$ $=7.14 \mathrm{~kW}$. As indicated above, the decay heat gradually decreases during the succeeding period of SNF storage, and the data from study [6] are used.

A scheme of heat transfer from the fuel rods through the cask is presented in Figure 2. The heat from the fuel load by conduction is transferred to the outer surfaces of the cask, and then by radiation and natural convection to the environment. For the modeling, effective axial and radial heat conductivity coefficients were used to evaluate the heat transfer through the fuel load. They were obtained experimentally by research institutions.

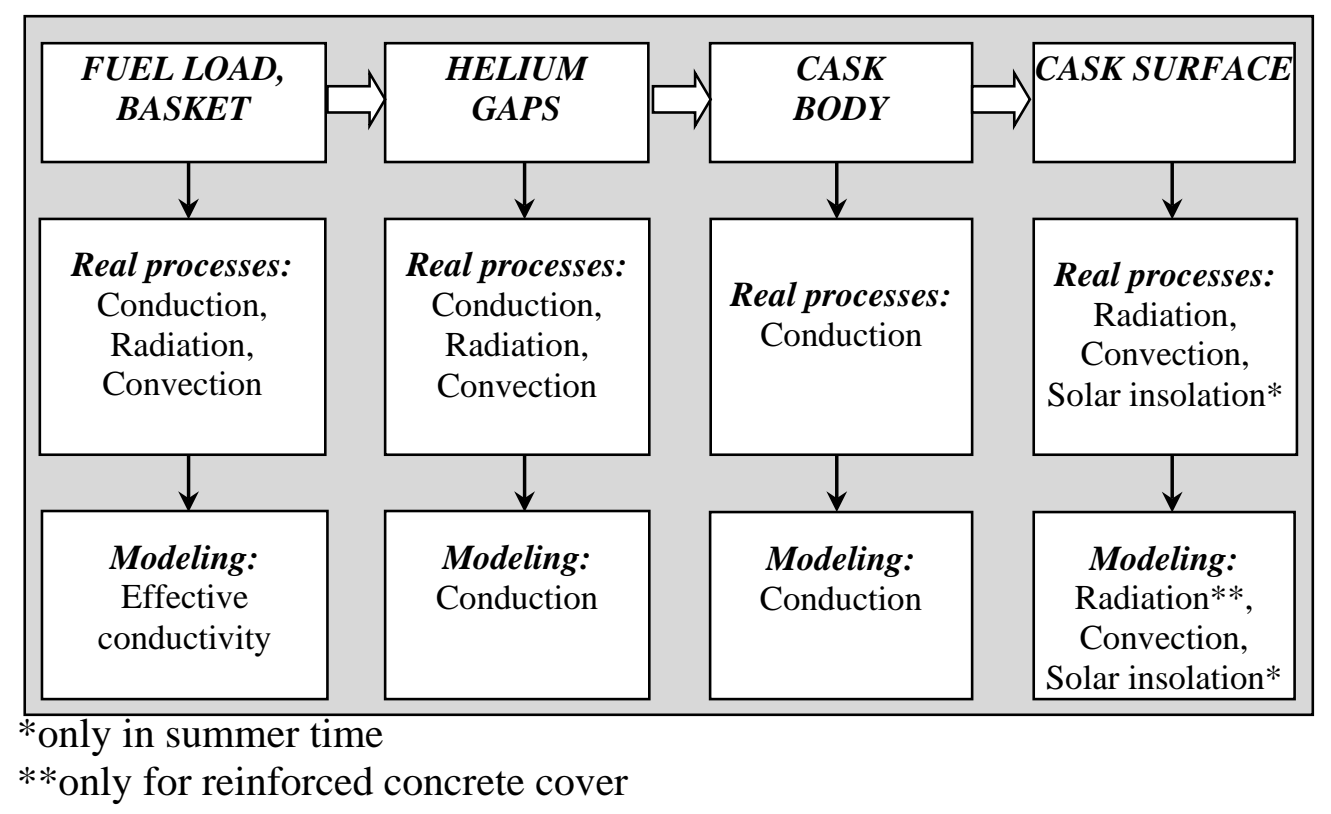

Fig. 2. Processes of decay heat removal from the cask.

For the determination of the heat transfer coefficient from the vertical cylindrical surface of the cask by natural convection an empirical correlation [22] was used:

$$
N u=0.13 R a^{1 / 3}
$$

where $N u=\alpha_{\text {conv }} l / \lambda_{0}$ is the Nusselt number; $R a=G r \operatorname{Pr}$ is the Rayleigh number; $G r=g \beta l^{3}\left(T_{\text {cask }}-T_{a}\right) / v_{0}{ }^{2}$ is the Grashof number; $\operatorname{Pr}=\mu_{0} C_{\mathrm{p}} / \lambda_{0}$ is the Prandtl number; $g=9.81 \mathrm{~m} / \mathrm{s}^{2}$ is the gravitational acceleration; $\beta$ is the coefficient of volumetric expansion; $\lambda_{0}, v_{0}$ and $\mu_{0}$ are coefficients of air conductivity and dynamic and kinematic viscosity, respectively; $C_{\mathrm{p} 0}$ is air specific heat, $l$ is a reference geometrical parameter. The reference geometrical parameter here is the cask's height, and the reference temperature is the ambient temperature. 
For the upper horizontal surface of the protective concrete cover of the cask the heat transfer coefficient is calculated from the empirical correlation [22]:

$$
N u=0.15 R a^{1 / 3}
$$

The reference geometrical parameter here is half of the cask's radius, and the reference temperature is the ambient temperature. The calculation of the parameters mentioned is a iterative process since the values of heat transfer coefficients and surface temperatures depend on each other.

For evaluating heat transfer through the He gaps, only conduction was taken into account. Based on $[23,24]$, an increase in heat transfer by natural convection is negligible when the parameter $R a$, characterizing natural convection, is less than 1000 . Heat transfer by radiation through the He gaps also can be neglected conservatively because the temperature differences in the He gaps are relatively small and He thermal conductivity is rather high.

In the modeling, heat from solar insolation was taken into account. This was evaluated based on IAEA recommendations [25]. It is recommended that the heat flux from solar insolation during daylight (12 hours) to horizontal surfaces is $800 \mathrm{~W} / \mathrm{m}^{2}$, and to vertical surfaces is $200 \mathrm{~W} / \mathrm{m}^{2}$. In this study heat fluxes from solar insolation were distributed during 24 hours. So, heat flux to the horizontal surface was $400 \mathrm{~W} / \mathrm{m}^{2}$ and to the vertical surface $100 \mathrm{~W} / \mathrm{m}^{2}$. Also, the effect of neighboring containers for vertical surfaces was taken into account, since, in a storage facility, casks are arranged at intervals of $3 \mathrm{~m}$.

Furthermore, heat radiation from the outer cylindrical surface of the cask to the environment was not taken into consideration because the wall temperatures of surrounding casks are similar. The summary of the real and modeled processes is presented in Figure 2.

In this study, when the modeled cask is in an open storage facility in summer time, it is affected by solar insolation and the ambient temperature is $37^{\circ} \mathrm{C}$. Such a temperature was evaluated by taking into account the average temperature of the hottest season in Lithuania and adding $10^{\circ} \mathrm{C}$ due to the effect of the adjacent casks. A decrease of the temperature during the night was conservatively not taken into account. Analysis was also performed for a case when the cask is in an open storage facility in winter time. In this case the solar insolation was neglected and the ambient temperature was $-42{ }^{\circ} \mathrm{C}$.

Further, the temperature and the heat flux distributions in the fuel load and the cask's body were modeled using the ALGOR code. An assumption was made that the maximum fuel load temperature coincides with the central heat generating rod temperature.

Modeling was performed for characteristic container storage periods: at 100, 200 and 300 years of storage but analysis include also the data [17] for just loaded casks with SNF pre-stored in water pools for 5 years and at 50 years storage. Validation of the numerical model was performed by comparing modelling results of cask surface temperatures with surface temperature measurements of a commercial cask for winter conditions (ambient temperature $-6^{\circ} \mathrm{C}$ taking into account real burnup of the loaded fuel bundles [26]. The surface temperature difference between modelling results and measurements was in the range of $0.5-2.0^{\circ} \mathrm{C}$.

After the identification of the parameters that could have the most significant impact on the temperature values in the cask, a local sensitivity analysis was performed by changing those parameters values by $\pm 20 \%$.

\section{Results}

\subsection{Analysis of the results for summer and winter conditions}

Figure 3 shows the distribution of isotherms in the casks for the fuel and the bodies of casks after 100 and 300 years of storage, when the ambient temperature is $37^{\circ} \mathrm{C}$. We can see from Figure 3(a), that the maximum temperature of the fuel load reaches nearly $112{ }^{\circ} \mathrm{C}$ in the case of 100 years of storage. The farther from the center, the lower the temperature. This is true for axial and for radial directions, but in the radial direction, the temperature decreases are much higher. For the cask body of course the highest temperatures are in the centers of the inner surfaces of the cask's body, the cask's bottom and the protective cover. The lowest temperatures are at the corners of the outside surfaces of the cask's body.

In the case of 300 years of storage (Figure 3(b)), the maximum fuel load temperature is about $20^{\circ} \mathrm{C}$ lower due to decreased decay heat, and it reaches about $92{ }^{\circ} \mathrm{C}$ but it is displaced to the top of the cask because 
of the effect of solar insolation. The surface temperatures decrease a little $-3-4^{\circ}$ in comparison with the temperatures in the case of 100 years of storage.

The common feature for both storage periods is that due to the conservative assumption on the influence of solar insolation [25] the temperatures of the upper surface of the protective cover are higher than the maximum temperatures of fuel load. The temperatures of the cask's outer cylindrical surfaces are lower than the outer surfaces temperatures of the protective concrete cover. This is because the solar intensity on horizontal surfaces is higher than on the cask's vertical surfaces and due to the shadow effect of the neighboring casks.

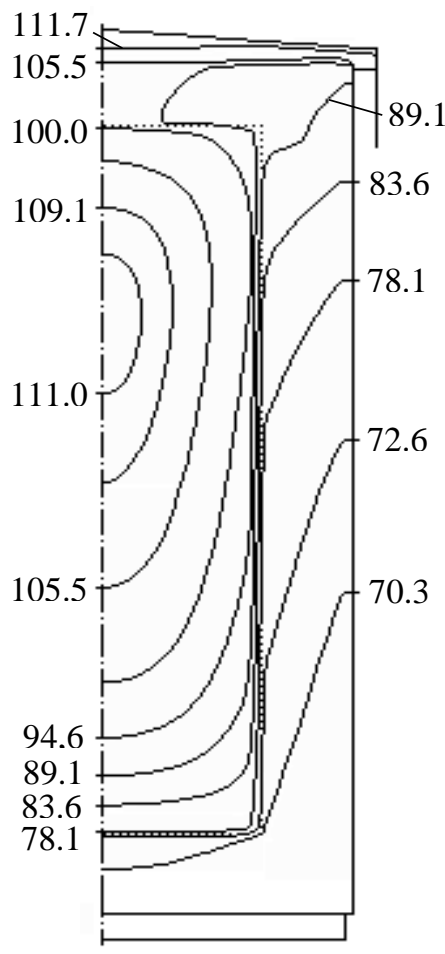

(a)

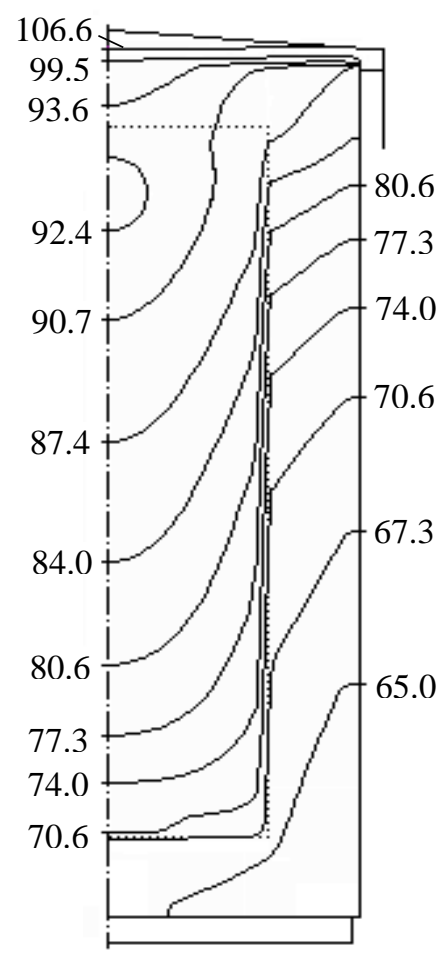

(b)

Fig. 3. Distribution of isotherms inside the casks for summer conditions: (a) in case of 100 years of storage; (b) in case of 300 years of storage.

Figure 4 presents typical axial temperature distributions in the casks during cask storage from 5 to 300 years for warm and cold conditions including the data of a study [16] on cask storage for 5 and 50 years. As it is seen in Figure 4(a), the maximum temperature in summer time is recorded in the center of the fuel load. Moving farther from the cask's center, the temperatures decrease gradually. We can see that in the areas of the He gaps there are significant temperature gradients. The temperatures change little at the bottom of the cask because of the better conductivity of the cask's body. The temperatures slightly increase at the top in the zone of the casks' lids for a sufficiently conservative assessment of the solar insolation. The maximum temperature displacement towards the top of the container after 100-300 years of casks storage can be seen as well. The temperatures vary the most in case of just loaded SNF (after 5 years pre-storage in water pools), and later the differences are decreasing.

The axial temperature distribution in winter time is presented in Figure 4(b). Here the maximum temperatures are also in the center of the casks for 5 years of SNF storage. In this case the influence of the solar insolation is not taken into account. The temperature distribution through the cask bottoms and through the cask lids is similar as in summer time.

Figure 5 presents characteristic radial temperature distributions in the casks during the whole period of cask storage, i. e., from 5 to 300 years in case of summer and winter conditions. Radial cross-sections are selected at the heights of 2.5-3.8 m where the fuel load temperatures are the highest. As the Figure demonstrates, the general picture of the radial temperature distributions is similar for summer (Figure 5(a)) and for winter (Figure 5(b)) conditions. Of course, there are quantitative differences in the temperatures, and moving away from the axis of the cask, the temperatures decrease monotonically. The temperatures change 
the most in the case of just loaded SNF (pre-stored for 5 years in water pools), and the highest temperature gradients are at a radius of $0.7-0.75 \mathrm{~m}$ in the outside zone of the basket and in the He gap. The temperatures do not really change over the body of the cask at the same height because it has good conductivity characteristics.

Figure 6 presents characteristics summarizing temperature distributions during the whole period of cask storage up to 300 years also considering the data from the study [16] on cask storage results after 5 and 50 years for summer (ambient temperature $37^{\circ} \mathrm{C}$ ) and winter (ambient temperature $-42{ }^{\circ} \mathrm{C}$ ) conditions.

As it is seen from Figure 6(a), and as it has been already mentioned above, the fuel load temperatures in summer time change mostly during 50 years of storage. Later the temperatures decrease slowly and reach 92 ${ }^{\circ} \mathrm{C}$ at 300 years of storage. The temperatures of the cask surfaces after 50 years of storage and later change very little. It is characteristic that under summer conditions (assessing the solar influence), the cask lid temperatures are higher than the temperatures of the side cylindrical surfaces and the bottom and after 100 years of storage even exceed the fuel load temperatures.

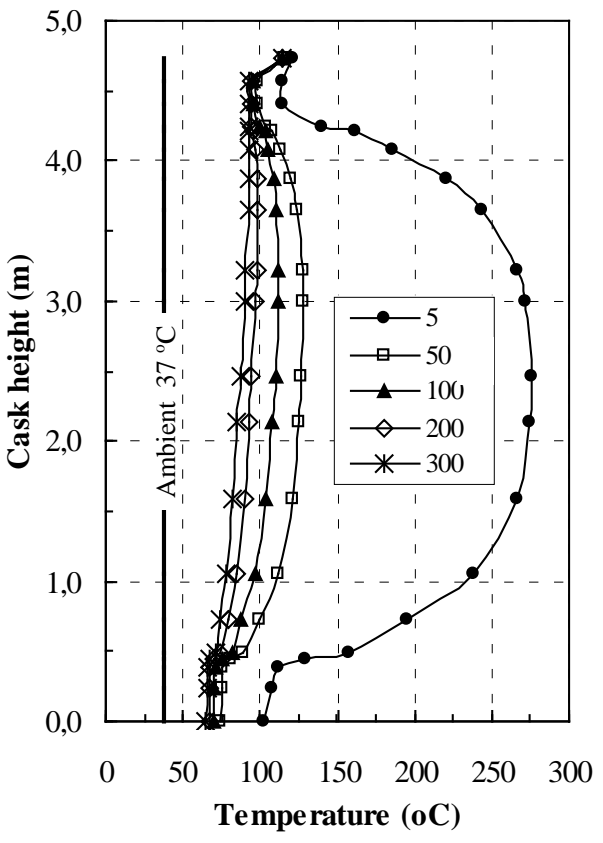

(a)

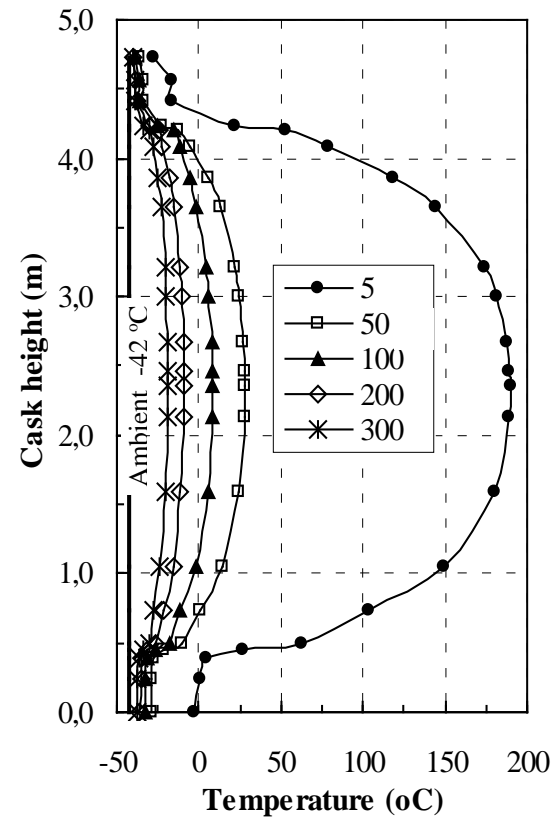

(b)

Fig. 4. Axial variation of the cask's temperatures with time: (a) for summer conditions; (b) for winter conditions.

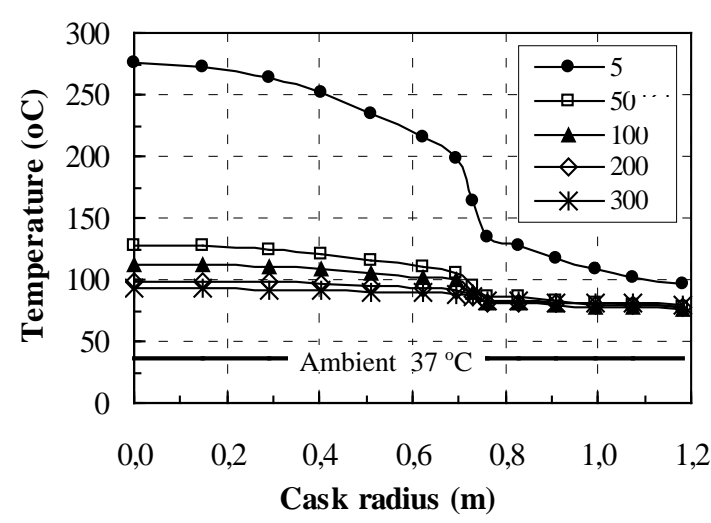

(a)

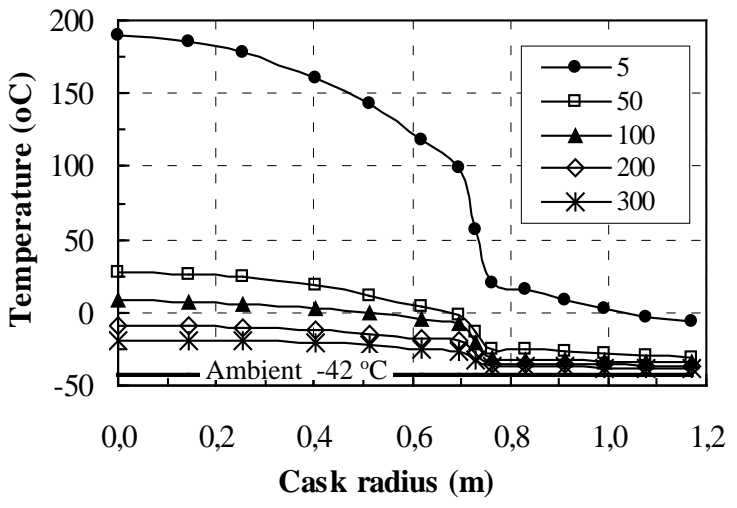

(b)

Fig. 5. Radial variation of the cask's temperatures with time: (a) for summer conditions; (b) for winter conditions. 


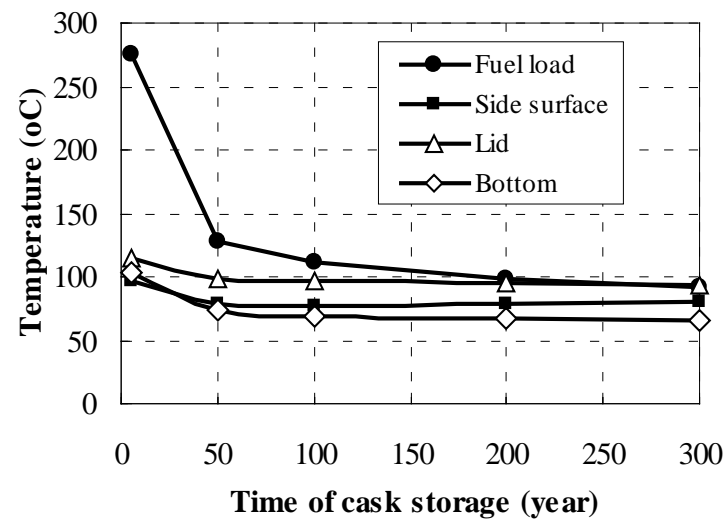

(a)

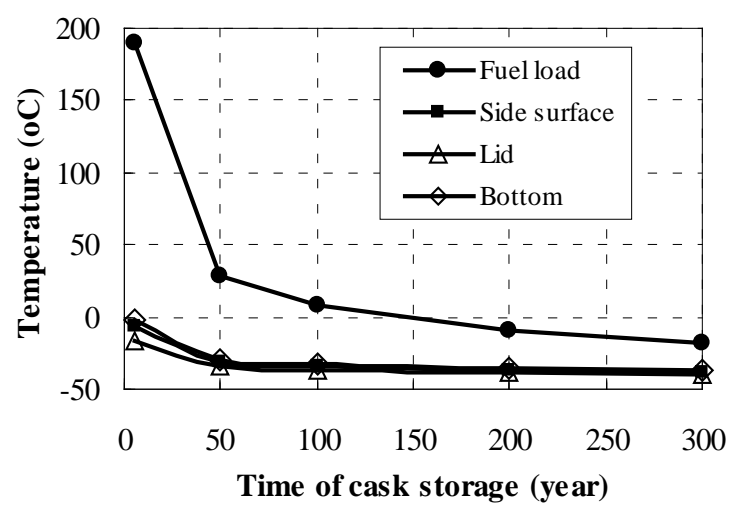

(b)

Fig. 6. Variation of fuel load and cask's characteristic surfaces temperatures with storage time: (a) for summer conditions; (b) for winter conditions.

The temperatures of the fuel load for winter conditions (Figure 6(b)) decrease significantly. We can see that after about 150 years of storage they are below zero. In the case of 300 years of storage the fuel load temperatures reach $-19{ }^{\circ} \mathrm{C}$. After about 100 years of storage, almost all cask surface temperatures become equal and reach -33 to $-39{ }^{\circ} \mathrm{C}$. Such low temperatures are not considered to be critical from the structural point of view and satisfy design criteria. Characteristic maximum temperatures of main cask elements during all periods of storage are presented in Table I.

Table I. Characteristic maximum temperatures of analyzed casks $\left({ }^{\circ} \mathrm{C}\right)$.

\begin{tabular}{|c|c|c|c|c|c|c|c|c|}
\hline \multirow[b]{2}{*}{ Modeling case } & \multicolumn{4}{|c|}{ In summer, $\mathrm{t}_{\mathrm{a}}=37^{\circ} \mathrm{C}$} & \multicolumn{4}{|c|}{ In winter, $\mathrm{t}_{\mathrm{a}}=-42^{\circ} \mathrm{C}$} \\
\hline & $\begin{array}{l}\text { Hottest } \\
\text { fuel load } \\
\text { spot }\end{array}$ & $\begin{array}{l}\text { Open cy- } \\
\text { lindrical } \\
\text { surface }\end{array}$ & $\begin{array}{l}\text { Upper } \\
\text { cask lid } \\
\text { surface }\end{array}$ & $\begin{array}{l}\text { Bottom } \\
\text { cask } \\
\text { surface }\end{array}$ & $\begin{array}{l}\text { Hottest } \\
\text { fuel load } \\
\text { spot }\end{array}$ & $\begin{array}{l}\text { Open cy- } \\
\text { lindrical } \\
\text { surface }\end{array}$ & $\begin{array}{c}\text { Upper } \\
\text { cask lid } \\
\text { surface }\end{array}$ & $\begin{array}{l}\text { Bottom } \\
\text { cask } \\
\text { surface }\end{array}$ \\
\hline $\begin{array}{l}\text { 1. Just loaded cask } \\
\text { (SNF is pre-stored for } 5 \\
\text { years in water pools) } \\
\text { [16] }\end{array}$ & 276.0 & 96.3 & 114.6 & 102.8 & 189.6 & -6.4 & -16.7 & -2.7 \\
\hline $\begin{array}{l}\text { 2. Cask at } 50 \text { years of } \\
\text { storage [16] }\end{array}$ & 128.0 & 78,3 & 98.6 & 73.7 & 27.8 & -30.4 & -33.7 & -29.4 \\
\hline $\begin{array}{l}\text { 3. Cask at } 100 \text { years of } \\
\text { storage }\end{array}$ & 111.8 & 76,4 & 96.0 & 69.4 & 8.3 & -34.6 & -36.6 & -33.2 \\
\hline $\begin{array}{l}\text { 4. Cask at } 200 \text { years of } \\
\text { storage }\end{array}$ & 98.7 & 78.4 & 94.3 & 66.6 & -9.3 & -36.8 & -38.3 & -35.9 \\
\hline $\begin{array}{l}\text { 5. Cask at } 300 \text { years of } \\
\text { storage }\end{array}$ & 92.6 & 79.7 & 93.4 & 65.1 & -18.7 & -38.1 & -39.2 & -37.4 \\
\hline
\end{tabular}

\subsection{Sensitivity analysis}

A sensitivity analysis was performed to estimate the effect of deviations from the parameter values used in the modeling on the maximum temperatures of characteristic cask elements - fuel load and side cylindrical surface. During storage the cask surfaces are protected against atmospheric conditions by suitable coatings of cask cavity and of external surfaces of the cask. The external surfaces are sufficiently protected from corrosion by a multilayered paint coating that can be checked and repaired if damaged because active control of the storage facility will be performed during the whole storage period (up to 300 years). So, based on this, it was assumed that thermal properties of the cask body and its surface will not change. Finally five parameters were identified that could significantly affect the characteristic temperatures of the cask. They were: 
- Heat load of SNF. Its value depends on various parameters: nuclear fuel type, its enrichment, assessment of its pre-storage time, its housing in the cask, etc.

- Effective thermal conductivity coefficient of fuel load. The fuel load consists of a basket with basket tubes where fuel rod bundles are placed. It is filled with He. The effective conductivity coefficient is defined experimentally by design institutions and, of course, with certain assumptions and uncertainties.

- Thermal conductivity coefficient of the gaps filled with He. Heat is transferred here not only by conduction, but effects of natural convection and radiation were neglected in Section 3.

- Ambient temperature. This temperature takes into account the effect of the adjacent casks, but, of course, with some uncertainties.

- Heat flux from solar insolation. Assumed values of solar insolation are rather conservative, but, of course, with some uncertainties.

The same parameters variation range $( \pm 20 \%)$ was assumed for all parameters with the purpose to reveal the parameters that can have most significant impact on the maximum temperatures of fuel load and the outer cylindrical surface was estimated for just loaded SNF (after 5 years pre-storage in the water pools) and at 100 years of dry storage. Based on this information it is easy to define the possible impact in real conditions (time and season). The influence of the identified parameters on the change of the maximum temperatures is expressed through Tornado diagrams and is presented in Figures 7 and 8. As we can see from Figure 7(a) for just loaded SNF the uncertainty of heat load has the largest effect on the change of the maximum fuel rod temperature (about $\pm 13 \%$ ). This means that the maximum fuel rod temperature could reach about $311^{\circ} \mathrm{C}$. It slightly exceeds the $300{ }^{\circ} \mathrm{C}$ limit [4], but it is smaller than the limit of $350{ }^{\circ} \mathrm{C}$ [5]. The influence of other parameter uncertainties is much smaller.

At 100 years of cask storage (Figure 7(b)), the ambient temperature uncertainty has the most significant impact on maximum fuel rod temperature (about $\pm 8 \%$ ). Impact of the other analyzed parameter uncertainties is smaller.

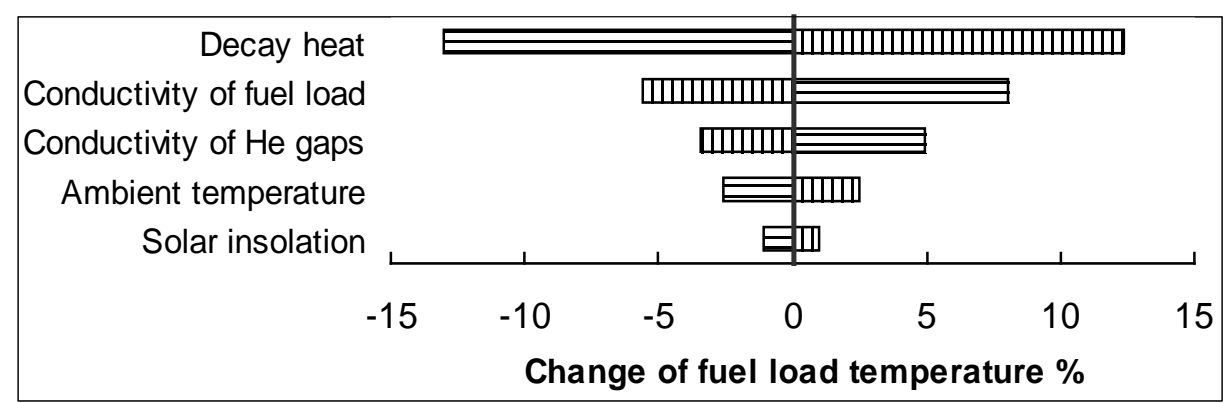

(a)

\begin{tabular}{|c|c|c|c|}
\hline Ambient temperature & E & |⿱㇒⿴囗夊 & \\
\hline Decay heat & & 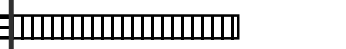 & \\
\hline Solar insolation & & 青血血血血 & \\
\hline Conductivity of fuel load & एسmسm & 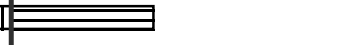 & \\
\hline Conductivity of He gaps & 世盂 & 鹤要 & \\
\hline-10 & -5 & 5 & 10 \\
\hline \multicolumn{4}{|c|}{ Change of fuel load temperature \% } \\
\hline
\end{tabular}

(b)

Fig. 7. Sensitivity assessment of the changes of the maximum fuel rod temperature for summer time: (a) for just loaded SNF; (b) at 100 years of dry storage.

However, the effect of the uncertainties of these selected parameters on the temperature of the cask's outside cylindrical surfaces is different. In this case, the ambient temperature has the largest impact on the temperature change of the outer cylindrical surface for just loaded SNF (Figure 8(a)) and at 100 years of dry storage (Figure 8(b)) (about $\pm 8 \%$ and about $\pm 11 \%$, respectively). The heat load uncertainty is rather important 
for just loaded fuel case (about $\pm 6 \%$ ), and uncertainty in solar insolation is rather important at 100 years of dry storage (about $\pm 6 \%$ ). The uncertainties of effective conductivity of fuel load and of the He gaps conductivity have little impact.

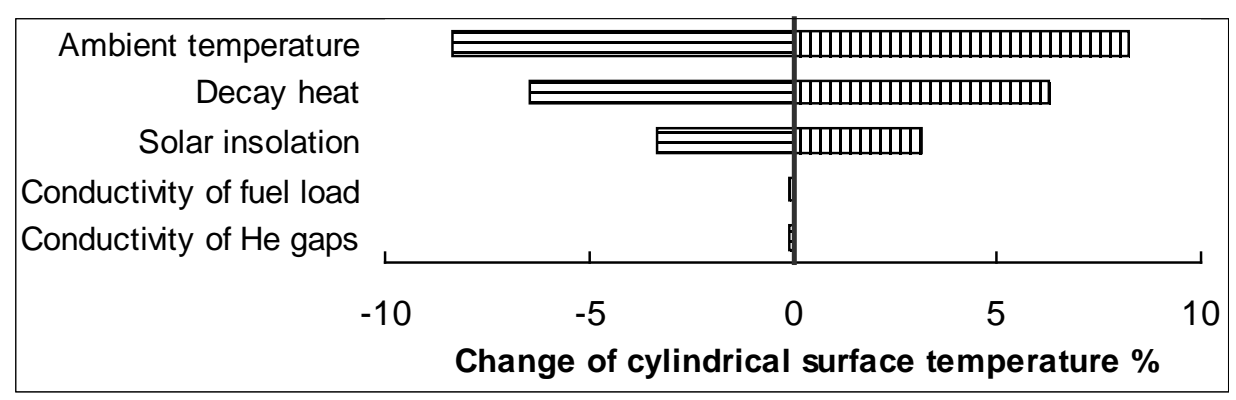

(a)

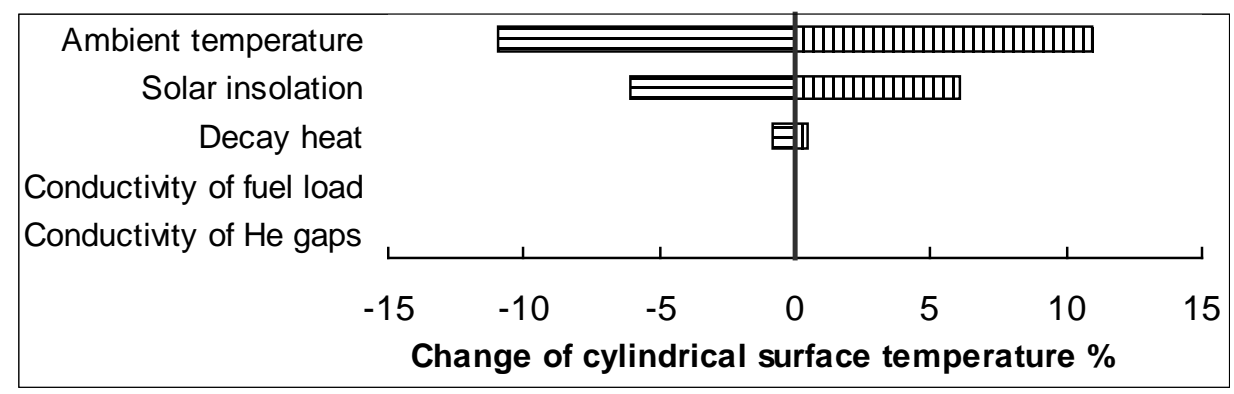

(b)

Fig. 8. Sensitivity assessment of the changes of the outer cylindrical surface temperature for summer time: (a) for just loaded SNF; (b) at 100 years of dry storage.

\section{Conclusions}

The following conclusions have been made after a detailed analysis for decay heat removal from CONSTOR RBMK-1500 casks loaded with SNF during long-term storage up to 300 years at the INPP in an open dry storage facility for summer and winter conditions using the numerical modeling code ALGOR:

1. The rather significant decrease of fuel load temperatures is until 50 years of dry storage. Later on, the temperatures gradually decrease and the maximum fuel rod temperature in summer after 300 years of storage reaches $92{ }^{\circ} \mathrm{C}$. For winter conditions, this temperature after 300 years of storage reaches $-19{ }^{\circ} \mathrm{C}$. The temperatures of the casks' outer surfaces after 50 years of dry storage change vary insignificantly.

2. The sensitivity analysis showed that the maximum fuel rod temperature could be about $311^{\circ} \mathrm{C}$, and that it does not exceed the limit of $350^{\circ} \mathrm{C}$.

3. From the thermal point of view CONSTOR RBMK-1500 casks meet the requirements for dry storage of spent nuclear fuel in the interim period of storage up to 50 years and for the subsequent long-term storage period up to 300 years.

\section{References}

1. A. G. Olabi. $100 \%$ sustainable energy, Energy, 77, 1-5 https://doi.org/10.1016/j.energy.2014.10.083

2. A. G. Olabi. Renewable energy and energy storage systems, Energy, 136, 1-6 (2017). https://doi.org/10.1016/j.energy.2017.07.054

3. H. Jouhara, A. G. Olabi. Editorial: Industrial waste heat recovery, Energy, 160, 1-2 (2018). https://doi.org/10.1016/j.energy.2018.07.013 
4. V. I. Kalinkin, V. G. Kritskij, N. N. Davidenko et al. Technology of SNF RBMK-1500 Transfer from "Wet" to "Dry“ Storage. JSC "Head Institute VNIPIET" and JSC "Concern Rosenergoatom", St. Petersburg, Russia (2010).

5. A. V. Vatulin, A. G. Ioltukhovskiy, I. M. Kadarmetov et al. Validation of dry storage modes for RBMK1000 spent fuel assembles (SFA) (IAEA-CN-102/39). In: Storage of Spent Fuel from Power Reactors, Proc. IAEA International Conference, Vienna (2003).

6. A. Šmaižys, P. Poškas, E. Narkūnas, G. Bartkus. Numerical modelling of radionuclide inventory for RBMK irradiated nuclear fuel, Nuclear Engineering and Design, 277, 28-35 (2014). https://doi.org/10.1016/j.nucengdes.2014.06.014

7. J. C. Lee, K. S. Bang, K. S. Seo, H. D. Kim, B. I. Choi, H. Y. Lee, Thermal analysis of a spent fuel storage cask under normal and off-normal conditions. J. Korean Radioactive Waste Society, 2, 1, 13-22 (2004).

8. J. C. Lee, W. S. Choi, K. S. Bang, K. S. Seo, S. Y. Yoo, Thermal-fluid flow analysis and demonstration test of a spent fuel storage system. Nuclear Engineering and Design, 239, 3, 551-558 (2009). https://doi.org/10.1016/j.nucengdes.2008.12.015

9. Y. S. Tseng, J. R. Wang, F. P. Tsai, Y. H. Cheng, C. Shih, Thermal design investigation of a new tubetype dry-storage system through CFD simulations. Annals of Nuclear Energy, 38, 5, 1088-1097 (2011). https://doi.org/10.1016/j.anucene.2011.01.001

10. J. Li, Y. Y. Liu. Thermal modelling of a vertical dry storage cask for used nuclear fuel, Nuclear Engineering and Design, 301, 74-88 (2016). https://doi.org/10.1016/j.nucengdes.2016.01.008

11. S. Alyokhina, V. Goloshchapov, A. Kostikov, Yu. Matsevity, Simulation of thermal state of containers with spent nuclear fuel: multi-stage approach, International Journal of Energy Research, 39, 1917-1924 (2015). https://doi.org/10.1002/er.3387

12. S. Alyokhina, A. Kostikov, S. Kruhlov, Safety issues of the dry storage of the spent nuclear fuel, Problems of Atomic Science and Technology, 108, 70-74 (2017).

13. S. V. Alyokhina, S. S. Kapuza, A. O. Kostikov, Solar radiation influence onto the spent nuclear fuel dry storage container, Problems of Atomic Science and Technology, 114, 57-62 (2018).

14. S. H. Yoo, H. C. No, H. M. Kim, E. H. Lee, Full-scope simulation of a dry storage cask using computational fluid dynamics, Nuclear Engineering and Design, 240, 12, 4111-4122 (2010). https://doi.org/10.1016/j.nucengdes.2010.08.009

15. R. A. Brewster, E. Baglietto, E. Volpenhein, C. S. Bajwa, CFD analyses of the TN-24p PWR spent fuel storage cask, Proc. of ASME Pressure Vessels \& Piping Division Conference, Paper No. PVP2012-78491, Toronto (2012).

16. P. Poškas, A. Šmaižys, V. Šimonis. Radiological and thermal characteristics of CASTOR RBMK-1500 and CONSTOR RBMK-1500 casks for spent nuclear fuel storage at Ignalina Nuclear Power Plant, Kerntechnik, 71, 222-227 (2006). https://doi.org/10.3139/124.100297

17. R. Poškas, V. Šimonis, P. Poškas, A. Sirvydas. Thermal analysis of CASTOR RBMK-1500 casks during long-term storage of spent nuclear fuel, Annals of Nuclear Energy, 99, 40-46 (2017). https://doi.org/10.1016/j.anucene.2016.09.031

18. Verifying the safety of a radioactive waste container with simulation software. Physical Sciences, (2005). https://www.techbriefs.com/component/content/article/tb/techbriefs/physical-sciences/495

19. Y. Li, W. Y. Liu, S. Frimpong, Effect of ambient temperature on stress, deformation and temperature of dump truck tire, Engineering Failure Analysis, 23, 55-62 (2012). https://doi.org/10.1016/j.engfailanal.2012.02.004

20. R. B. Pandit, S. Prasad, Finite element analysis of microwave heating of potato-transient temperature profiles, Journal of Food Engineering, 60, 2, 193-202 (2003). https://doi.org/10.1016/S02608774(03)00040-2

21. C. S. Y. Lee, S. G. Kim, S. Y. Jeong, S. H. Ahn, W. H. Jin, S. S. Jang, I. J. Cho, Y. S. Kim, H. J. Nam, Thermal analysis of micro cantilevers integrated with heaters for low power nano-data-storage application, Sensors and Actuators A: Physical, 139, 1-2, 12-16 (2007).

22.

23.

24. 
25.

26. S. S. Kutateladze. Heat Transfer and Flow Resistance. Handbook. Energoatomizdat: Moscow (1990).

27. Heat transfer by free convection in closed fluid layers. VDI Heat Atlas, Editon 6 (1991).

28. M. A. Mikheyev, I. M. Mikheyeva. Basics of heat transfer. Energy: Moscow (1977).

29. Regulations for the Safe Transport of Radioactive Material. 2012 Edition. IAEA Safety Standards Series. Specific Safety Requirements No. SSR-6. IAEA, Vienna (2012).

30. V. Šimonis, P. Poškas, A. Šmaižys, Temperature distribution assessment for spent nuclear fuel casks at the Ignalina NPP storage facility, Power Engineering, 54, 2, 10-14 (2008).

\section{Declaration of interest}

Conflicts of interest: none

\section{Role of the funding sources}

This research did not receive any specific grant from funding agencies in the public, commercial, or not-forprofit sectors. 